\title{
Second trimester placental thickness: its' correlation with gestational age, femur length and biparietal diameter
}

\author{
Sandesh Ganjoo ${ }^{1 *}$, Shalini Devgan ${ }^{2}$, Ghanshyam Dev ${ }^{3}$
}

\begin{abstract}
${ }^{1}$ Department of Obstetrics and Gynecology, ${ }^{2}$ Department of Community Medicine, Guru Gobind Singh Medical College and Hospital, Faridkot, Punjab, India

${ }^{3}$ Department of Radiology, Government Medical College, Jammu, Jammu and Kashmir
\end{abstract}

Received: 08 August 2018

Accepted: 13 August 2018

\section{*Correspondence:}

Dr. Sandesh Ganjoo,

E-mail: drsandeshganjoo@hotmail.com

Copyright: ( $)$ the author(s), publisher and licensee Medip Academy. This is an open-access article distributed under the terms of the Creative Commons Attribution Non-Commercial License, which permits unrestricted non-commercial use, distribution, and reproduction in any medium, provided the original work is properly cited.

\begin{abstract}
Background: Placental thickness (PT) is the easiest placental dimension to measure, yet little is known about the normal PT. The aim of this study was to determine the normal, sonographically measured PT in millimetre ( $\mathrm{mm}$ ) in the second trimester and to determine if this measurement can be adjusted for gestational age for that time and evaluate its relationship with femur length and biparietal diameter of the fetus.

Methods: The study was a cross sectional observational study, recruiting 100 consecutive, singleton pregnancies, reporting for ultrasonography (USG) between 14 weeks and 24 weeks of gestation, having undergone at least one ultrasonogram in the first trimester, with known last menstrual period (LMP). The placental thickness was measured perpendicular to the uterine wall, through the placenta at the site of cord insertion.

Results: The average age of study population was 24.96 with a standard deviation (SD) of 2.70 years with the minimum age being 18 years and maximum age being 32 years. Regression analysis yielded the following mathematical relationships between PT, Gestational age (GA), Biparietal diameter (BPD) and Femur length (FL) in the second trimester. $\mathrm{Y}(\mathrm{PT})=0.9366 \mathrm{x}$ (Gestation age $)+1.655, \mathrm{R}^{2}=0.7332 ; \mathrm{Y}(\mathrm{PT})=0.2872 \times(\mathrm{BPD})+6.9578, \mathrm{R}^{2}=$ $0.7314 ; \mathrm{Y}(\mathrm{PT})=0.2995 \times(\mathrm{FL})+10.03, \mathrm{R}^{2}=0.6186$

Conclusions: PT in present study showed a positive linear correlation with gestational age, FL and BPD in second trimester. Also, it can be concluded that PT may be used as a predictor of GA in women with unknown LMP.
\end{abstract}

Keywords: Biparietal diameter, Femur length, Gestational age, Placental thickness

\section{INTRODUCTION}

Placenta formation begins in the later half of the $2^{\text {nd }}$ month of pregnancy, is usually completed by $4^{\text {th }}$ month and reaches its maximum growth at term, ${ }^{1}$ when it is discoid in shape with a diameter of 15 to $25 \mathrm{~cm}$ and approximately $3 \mathrm{~cm}$ thick and weighs about 500 to 600 g. ${ }^{2}$ Placenta is a fetal organ with important metabolic, endocrine and immunologic functions besides being responsible for nutrition, respiration and excretion of fetus. Last but not least, it has a role in protecting the fetus from noxious agents. ${ }^{3}$

The in utero environment and its impact on neonatal health have been postulated to have a direct bearing on the health of an individual during later years. ${ }^{4,5}$ Research has shown a direct link between placental insufficiency and birth weight and its co-relation with development of the so called metabolic syndrome: hypertension, diabetes and coronary heart disease in later life. ${ }^{6}$ Placenta is the 
first organ to manifest changes of disease in pregnancy and therefore, screening of placenta may have a role in screening for diseases of pregnancy. Placenta and its functioning are known to influence the fetal birth weight and therefore, abnormalities if any in the placenta, would precede the abnormalities in fetal growth. ${ }^{7}$

Placental thickness (PT) is the easiest placental dimension to measure, yet little is known about the normal PT, measured by the second trimester sonography. ${ }^{8}$ The PT tends to gradually increase with gestational age in a linear fashion. Sonographically, it has been seen to be at about $1 \mathrm{~mm}$ per week. ${ }^{9}$ The maximum thickness of a normal placenta at any point during pregnancy is considered to be $4 \mathrm{~cm}$ and anything more than $4 \mathrm{~cm}$ is considered abnormal ${ }^{10}$ and associated with poor outcomes. ${ }^{11}$ A PT of less than $2.5 \mathrm{~cm}$ is usually associated with intra uterine growth restriction. ${ }^{12}$ There is not enough supporting literature for these cut off values, with the PT tending to vary according to its site of insertion, further casting a doubt on the cut off values.

Small and large, both placentae are associated with abnormalities, therefore second trimester screening of placentae could help in screening of potential complications. For this though, we need to establish what is normal first. To find out normal development of placenta, PT justifies as a good forecaster for fetal growth and birth weight, especially in the second trimester. ${ }^{13}$

The aim of this study was to determine the normal, sonographically measured PT in millimetre $(\mathrm{mm})$ in the second trimester and to determine if this measurement can be adjusted for gestational age for that time and evaluate its relationship with femur length and biparietal diameter of the fetus.

\section{METHODS}

The study was a cross sectional observational study, recruiting 100 consecutive, singleton pregnancies, reporting for ultrasonography (USG) between 14 weeks and 24 weeks of gestation, having undergone at least one ultrasonogram in the first trimester, with known last menstrual period (LMP).

Patients with diabetes, hypertension, anaemia, fetal anomalies, multiple pregnancies, placenta previa, posterior placenta, IUGR and unknown LMP were excluded from the study. The study was approved by Institutions Ethics Committee and a written informed consent was obtained from all patients.

The placental thickness was measured perpendicular to the uterine wall, through the placenta at the site of cord insertion. To maintain consistency, measurements were taken by a single operator. Along with placental thickness, biparietal diameter (BPD) and Femur length (FL) were also recorded.

\section{Statistical analysis}

Demographic data was presented as mean ( \pm standard deviation), median ( $25^{\text {th }}$ to $75^{\text {th }}$ percentiles) and number (percentage) according to distribution. Pearson's correlation analysis was used to establish degree of relationship between PT, FL and BPD. Mathematical relationships between PT, Gestational age (GA), FL and BPD were derived by regression analysis and the best fit model was used to plot the linear graphs of relationship between PT with GA, FL and BPD. The values were expressed as mean \pm standard deviation. Statistical tests were two tailed with $\mathrm{p}$ value $<0.01$ to indicate statistical significance. Data was analysed using SPSS software v.20.0 and Microsoft excel.

\section{RESULTS}

We observed a total of 100 patients, whose placental thickness was measured in their second trimester of pregnancy. The demographic details are presented in Table 1.

Table 1: Patient demographics $(n=100)$.

\begin{tabular}{|ll|}
\hline Characteristic & Mean (SD) Value \\
\hline Age, yrs & $24.96(2.70)$ \\
\hline Height, cms & $158.8(3.17)$ \\
\hline Weight, kg & $62(57-68)$ \\
\hline Body mass index, $\mathrm{kg} / \mathrm{m}^{2}$ & $25(23-27)$ \\
\hline Gestation, d & $144(20.8)$ \\
\hline Gestation, wk & $20.5(2.9)$ \\
\hline Gravida & $1.27(1-2)$ \\
\hline Parity & $0.22(0-1)$ \\
\hline Biparietal diameter & $44.34(9.3)$ \\
\hline Femur length & $32.27(8.24)$ \\
\hline
\end{tabular}

The average age of study population was 24.96 with a standard deviation (SD) of 2.70 years with the minimum age being 18 years and maximum age being 32 years. Maximum number of patients belonged to 12 to 25 years age group with an average BMI of $25 \mathrm{~kg} / \mathrm{m}^{2}$.

Table 2: Placental thickness for each week of gestation.

\begin{tabular}{|lllll|}
\hline $\begin{array}{l}\text { Gestation in } \\
\text { weeks+days }\end{array}$ & n & Mean & $\begin{array}{l}\text { Standard } \\
\text { deviation }\end{array}$ & $\begin{array}{l}\text { 95\% Confidence } \\
\text { intervals }\end{array}$ \\
\hline $14-14+6$ & 3 & 14.70 & 2.25 & $29.4(9.1-20.2)$ \\
\hline $15-15+6$ & 8 & 15.57 & 1.53 & $31.1(14.2-16.8)$ \\
\hline $16-16+6$ & 13 & 16.29 & 1.84 & $32.5(15.1-17.4)$ \\
\hline $17-17+6$ & 11 & 17.36 & 1.67 & $34.7(16.2-18.4)$ \\
\hline $18-18+6$ & 11 & 19.26 & 1.55 & $38.5(18.2-20.3)$ \\
\hline $19-19+6$ & 3 & 20.53 & 1.27 & $41.0(17.3-23.6)$ \\
\hline $20-20+6$ & 2 & 18.75 & 1.20 & $37.5(7.9-29.5)$ \\
\hline $21-21+6$ & 16 & 21.88 & 1.04 & $43.7(21.3-22.4)$ \\
\hline $22-22+6$ & 21 & 21.94 & 1.63 & $43.8(21.2-22.6)$ \\
\hline $23-23+6$ & 12 & 22.98 & 1.92 & $45.9(21.7-24.2)$ \\
\hline
\end{tabular}


Maximum patients belonged to gestational age of 22 weeks to 22 weeks 6 days and minimum number of patients belonged to 20 weeks to $22+6$ weeks.

The result of present study showed a fairly linear increase in PT with gestational age (Table 2).

There was a significant positive correlation between PT, GA, BPD and FL in the second trimester, with a 2 tailed Pearson's correlation returning a significance of 0.001 .

Regression analysis yielded the following mathematical relationships between PT, GA, BPD and FL in the second trimester.

- $\quad \mathrm{Y}(\mathrm{PT})=0.9366 \mathrm{x}($ Gestation age $)+1.655, \mathrm{R}^{2}=0.7332$

- $\mathrm{Y}(\mathrm{PT})=0.2872 \mathrm{x}(\mathrm{BPD})+6.9578, \mathrm{R}^{2}=0.7314$

- $\mathrm{Y}(\mathrm{PT})=0.2995 \mathrm{x}(\mathrm{FL})+10.03, \mathrm{R}^{2}=0.6186$

The scatter plots for the same are depicted in Figure 1, Figure 2 and Figure 3 respectively.

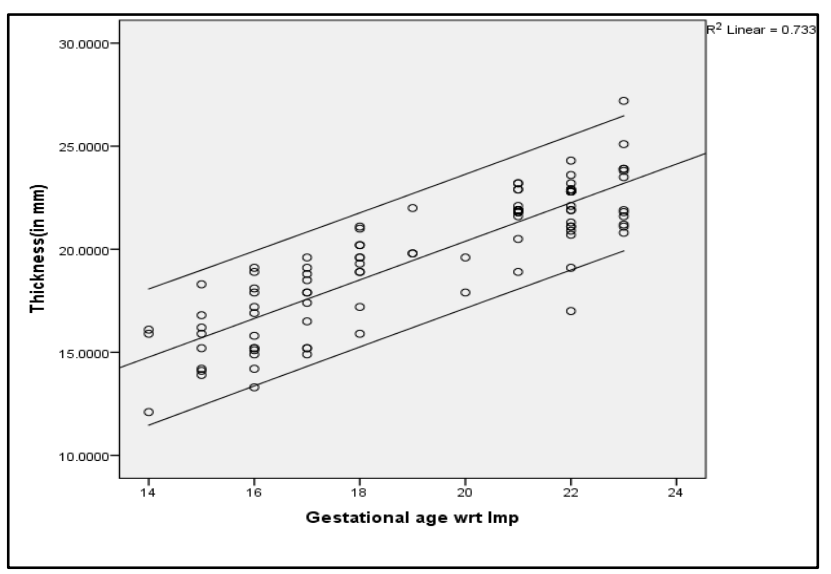

$y=0.9366 x+1.655 ; R^{2}=0.7332$

Figure 1: Scatter plot of PT versus gestational age.

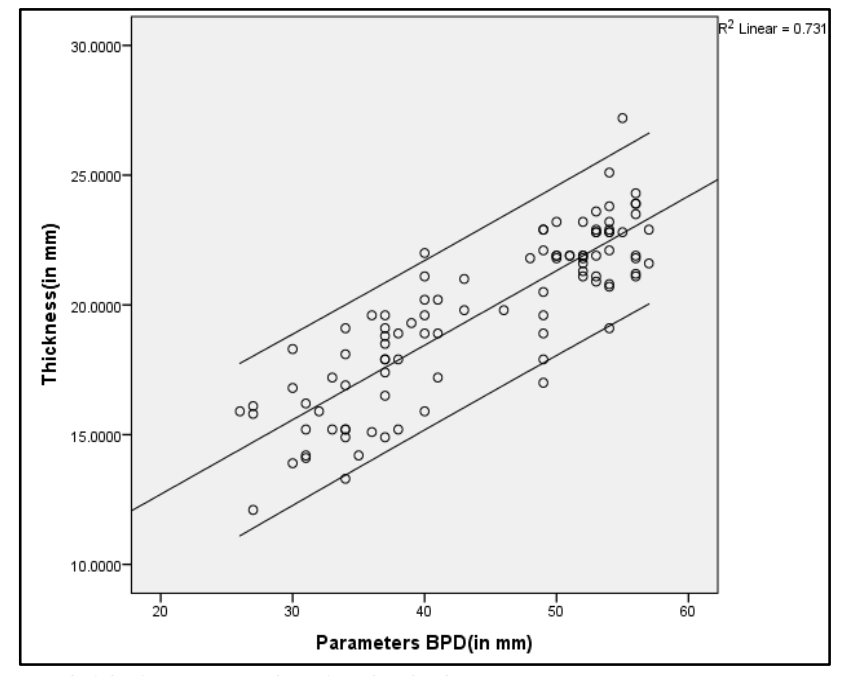

$y=0.2872 x+6.9578 ; R^{2}=0.7314$

Figure 2: Scatter plot of PT versus BPD.

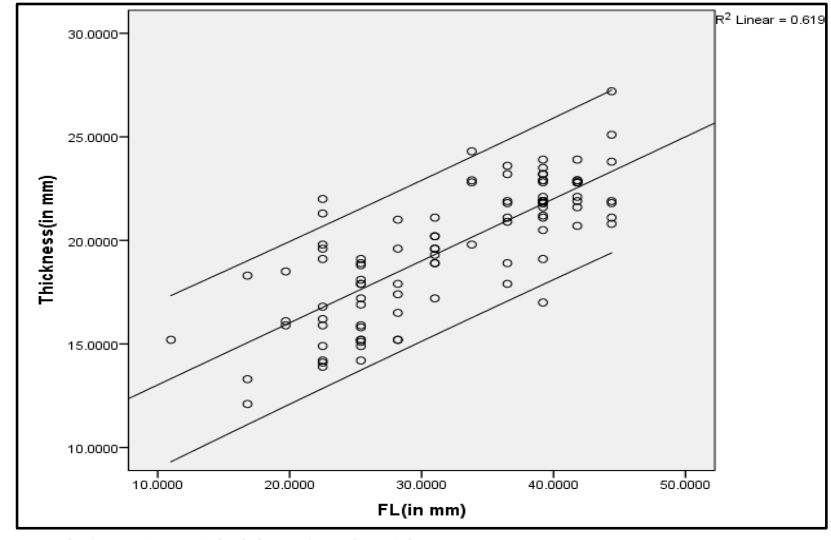

$y=0.2995 x+10.03 ; R^{2}=0.6186$

Figure 3: Scatter plot of PT versus FL.

\section{DISCUSSION}

In the present study the mean age of patients presenting in the second trimester was 24.96 years whereas in a study by Maryam et el the mean age was 26.4 years. ${ }^{14}$ In another study by Lee et al the average age was found to be 33.2 years which was higher than present study. ${ }^{8}$ This can be explained by the fact that in this part of the world, marriages at early age followed by early conception are a norm. Patients with average BMI of $25 \mathrm{~kg} / \mathrm{m}^{2}$ presented in present study.

As evident from Table 2, the mean gestational age along with SD corresponded to the PT and a linear increase was evident. Study by Karthikeyan $\mathrm{T}$ et al showed a similar linear increase. From $14^{\text {th }}$ to $19^{\text {th }}$ week, the increase in PT was about $5 \mathrm{~mm}$. In the $19^{\text {th }}$ and $20^{\text {th }}$ week the PT decreased by about $2 \mathrm{~mm}$. From $19^{\text {th }}$ to $24^{\text {th }}$ week there was an increase of about $3 \mathrm{~mm} .{ }^{15}$ These findings were consistent with study conducted by Ohagwu et al. ${ }^{16}$ At no point did we find a patient with placental thickness of more than $4 \mathrm{~cm}$, thus the fact that PT more than $4 \mathrm{~cm}$ is associated with abnormality could not be assessed and thus cannot be refuted.

In the present study, positive correlation between PT, FL and BPD in the second trimester was observed, which correlates with similar results from other studies also. Study conducted by Suresh K has similar observations. ${ }^{13}$ Another study conducted by Adhikari R et al, observed a positive significant correlation between PT, FL and BPD in second and third trimister. ${ }^{17}$ Ohagawu et al studied a significant correlation between PT and FL, BPD, AC and HC. ${ }^{16}$

The present study showed a positive correlation between PT and BPD. In present study PT did not correspond to gestational ages at 18,19 and 20 weeks. Mittal P et el reported comparable observation, that PT was higher by 1 to $4 \mathrm{~mm}$ between 10 to 21 weeks of gestation. ${ }^{18}$ In present study in the $18^{\text {th }}$ week and $19^{\text {th }}$ weeks, it was $1.25 \mathrm{~mm}$ and $2 \mathrm{~mm}$ higher respectively and in the $20^{\text {th }}$ week, it was $1.25 \mathrm{~mm}$ lesser. Jain et el also observed 
placental thickness was higher than gestational age by 1 to $5 \mathrm{~mm}$ between 10 to 25 weeks of gestation. ${ }^{3}$ Tiwari A et al showed PT was higher by 1 to $4 \mathrm{~mm}$ up to 21 weeks and after 22 weeks it was lower by 1 to $2 \mathrm{~mm} .{ }^{19}$ Present study observed linear correlation of PT with gestational age and also its positive significant relationship with FL and BPD in the second trimester.

Limitation of present study was that it was a cross sectional study and authors measured PT only once in each subject during the study. The sample size was small. Position of the placenta was not taken into account. PT might vary with the ethnicity of the data set and more sample sizes and from different ethnicity are required to test the efficacy of PT being used as a marker for fetal gestational age estimation.

\section{CONCLUSION}

PT in present study showed a positive linear correlation with gestational age, also its correlation with FL and BPD in second trimester was also linear. Also, it can be concluded that PT may be used as a predictor of GA in women with unknown LMP. In patients with abnormal parameters like BPD in hydrocephalus and FL in skeletal dysplasias, PT can be substituted for these parameters for gestational age estimation. In patients with abnormal PT for the corresponding gestational age, the underlying disease leading to increase or decrease of PT should be taken into account and rectified.

\section{ACKNOWLEDGMENTS}

Authors would like to thank Dr. Varun Kaul and Mr. Baltej Singh for their support during the study.

Funding: No funding sources Conflict of interest: None declared

Ethical approval: The study was approved by the Institutional Ethics Committee

\section{REFERENCES}

1. Cunningham FG, Gant NF, Leveno KS, Gilstap LC, Hanth JC, Wenstrom KD, in Williams Obstetrics, $21^{\text {st }}$ Ed. McGrawHill;2001:85-108.

2. Saddler TW, Langman's Medical Embryology. Baltimore ND. $9^{\text {th }}$ ed. Lippincot's Williams and Wilkins;2014:177-148.

3. Jain A, Ganesh K, Agarwal U, Kharakwal S. Placental thickness a sonographic indicator of gestational age. J Obst Gyne India. 2001;51(3):48-9.

4. Salafia CM, Maas E, Thorp JM, Eucker B, Pezzullo JC, Savitz DA. Measures of placental growth in relation to birth weight and gestational age. Am J Epidemiol. 2005;162:991-8.

5. Terry MB, Susser E. Commentary: the impact of fetal and infant exposures along the life course. Int $\mathbf{J}$ Epidemiol. 2001;30:95-6.

6. Barker DJP. Mothers, babies and disease in later life. London, England. British Med J Group. 1994.

7. Thame M, Osmond C, Wilks R, Bennett FL, Forrester TE. Second trimester placental volume and infant size at birth. Obst Gynecol. 2001;98:279-83.

8. Lee AJ, Bethune M, Hiscock RJ. Placental thickness in the second trimester: A pilot study to determine the normal range. J Ultrasound Med. 2012;31:213-218.

9. Thurston M, Weerakkody Y. Placental thickness. Available at https://radiopaedia.org/articles/placentalthickness Accessed on 2018 Aug 05.

10. Hoddick WK, Mahony BS, Callen PW, Filly RA. Placental thickness. J Ultrasound Med. 1985;4:479-82

11. Pinette $\mathrm{Mg}$, Pan $\mathrm{T}$, Blackstone J, Pinette SG. Ultrasound placental thickness measurements and pregnancy outcomes. Am J Obstet Gynecol. 1998;178(suppl):s167.

12. Kunlmann RS, Warsof S. Ultrasound of the placenta. Clin Obstet Gynecol. 1996;39:519-34.

13. Suresh KK, Bhagwat AR. Ultrasonographic measurement of placental thickness and its correlation with femur length. Int J Anat Radiol Surg. 2017 Jan;6(1):46-51.

14. Afrakhteh M, Moeini A, Taheri MS, Haghighatkhah HR. Correlation between placental thickness in the second and third trimester and fetal weight. Rev Bras Ginecol Obstet. 2013;35(7):317-22.

15. Karthikeyan T, Subramanium RK, Prabhu K. Placental thickness and its correlation to gestational age and fetal growth parameters-A cross sectional ultrasonographic study. J Clin Diagn Res. 2012 Dec;6(10):1732-5.

16. Ohagwu CC, Abu PO, Ezeokeke UO, Ugwu AC. Placental thickness: A sonographic indicator of gestational age in normal singleton pregnancies in Nigerian women. Internet J Med Update. 2009 July;4(2):9-14.

17. Adhikari R, Deka PK, Tayal A, Chettri PK. Ultrasonographic valuation of placental thickness in normal singleton pregnancies for estimation of gestational age. Int J Med Imaging. 2015;3(6):143-7.

18. Mittal P, Hooja N, Mehndiratta K. Placental thickness: a sonographic parameter for estimating gestational age of the fetus. Indian J Radiol Imaging. 2002;12(4):553-4.

19. Tiwari A, Chandnani K. A study to evaluate gestational age with the help of placental thickness. Int J Reprod Contracept Obstet Gynecol. 2013;2:503-5.

Cite this article as: Ganjoo S, Devgan S, Dev G. Second trimester placental thickness: its' correlation with gestational age, femur length and biparietal diameter. Int J Reprod Contracept Obstet Gynecol 2018;7:3568-71. 